\title{
Angústia de mulheres trabalhadoras de enfermagem que adoecem por distúrbios osteomusculares relacionados ao trabalho
}

\author{
Anguish of nursing women professionals who suffer from Work-Related Musculoskeletal Disorders (WRMD) \\ Angustia de trabajadoras de enfermería portadoras de disturbios osteomusculares relacionados al trabajo \\ Patrícia Campos Pavan Baptista', Miriam Aparecida Barbosa Merighi', Arlete Silva" \\ ' Universidade de São Paulo. Escola de Enfermagem. São Paulo-SP, Brasil. \\ "Universidade de Guarulhos. Guarulhos-SP, Brasil.
}

Submissão: 02/02/2010 Revisão: 16/11/2010 Aprovação: 20/11/2010

\begin{abstract}
RESUMO
Os distúrbios osteomusculares relacionados ao trabalho (DORT) representam uma doença crônica e incapacitante, que preocupa a saúde pública mundial. Este estudo qualitativo fenomenológico teve como objetivo compreender o fenômeno "ser mulher trabalhadora de enfermagem vivenciando DORT". Participaram seis trabalhadoras de enfermagem, portadoras de DORT, cujas entrevistas foram norteadas pela questão: Gostaria que você me contasse a sua experiência, como é para você ser mulher, trabalhadora de enfermagem, convivendo com um distúrbio osteomuscular relacionado ao trabalho? Os discursos foram analisados segundo o referencial de Martin Heidegger e os resultados evidenciaram que ser trabalhadora de enfermagem portadora de DORT é uma experiência marcada pela angústia, uma vez que o cotidiano dessas mulheres é marcado por dor, limitação e exclusão no ambiente de trabalho.
\end{abstract}

Descritores: Enfermagem; Transtornos traumáticos cumulativos; Saúde ocupacional.

\section{ABSTRACT}

Work-related musculoskeletal disorders (WRMD) represent a chronic and incapacitating disease, and a matter of concern to the public health worldwide. This qualitative phenomenological study aimed to reveal the phenomenon "being a female nursing professional living with WRMD". Six nursing professionals, suffering from WRMD, took part in the study. The interviews dealt with the guiding question: I would like you to tell me about your experience - how do you feel being a woman nursing professional, living with a work-related musculoskeletal disorder? Interviews were analyzed according to Martin Heidegger. Results showed that being a female nursing professional who suffers from WRMD is an experience which can give the anguish once the women daily is characterized by pain, limitations and prejudice in work environment.

Key words: Nursing; Cumulative trauma disorders; Occupational health.

\section{RESUMEN}

Los disturbios osteomusculares relacionados al trabajo (DORT), representan una enfermedad crónica e incapacitante, de carácter preocupante para la salud pública mundial. Este estudio de cualitativo fenomenológico ha buscado desvelar el fenómeno "ser mujer trabajadora de enfermería vivenciando DORT". Seis mujeres trabajadoras en enfermería, portadoras de DORT, fueran entrevistadas con la cuestión: Me gustaría que usted me contase su experiencia - como es para usted ser mujer, trabajadora de enfermería y conviviendo con disturbio osteomuscular relacionado al trabajo? Los discursos fueron analizados según Martin Heidegger. Los resultados demostraron que ser mujer, trabajadora de enfermería y portadora de DORT es una experiencia que hace emerger sentimientos de angustia, debido al cotidiano de esas mujeres, marcado por el dolor, limitaciones y prejuicio. Palabras clave: Enfermería; Trastornos traumáticos cumulativos; Salud laboral. 


\section{INTRODUÇÃO}

Os Distúrbios Osteomusculares Relacionados ao Trabalho (DORT) vêm assumindo um caráter epidêmico, pela expansão dos casos, gerando incapacidade para a vida que não se resume apenas ao ambiente de trabalho e, por conseguinte, acarretando fortes impactos no sistema de previdência pública e na distribuição do ônus para o conjunto da sociedade ${ }^{(1)}$.

Os DORT caracterizam-se por um processo crônico-degenerativo e psicossocial, onde vários aspectos contribuem para o seu surgimento, não havendo uma causa única e determinada para a sua ocorrência. Fatores como repetitividade de movimentos, manutenção de posturas inadequadas por tempo prolongado, esforço físico, pressão mecânica sobre determinados segmentos do corpo, principalmente membros superiores, trabalho muscular estático, impactos, vibração, frio, fatores organizacionais e psicossociais podem originar este distúrbio ${ }^{(2-4)}$.

A classificação dos DORT inclui um grupo heterogêneo de distúrbios funcionais e/ou orgânicos tais como as tenossinovites, tendinites, sinovites, peritendinites, em particular de ombros, cotovelos, síndromes compressivas dos nervos periféricos; além de sintomatologias mais disseminadas, como a síndrome miofascial, fibromialgia e distrofia simpático-reflexa ${ }^{(5)}$.

Atualmente sabe-se que os DORT não são originados apenas por lesões repetitivas, estando relacionados a diversas atividades, ocorrendo em uma multiplicidade de profissões. Vários estudos abordam os problemas do aparelho osteomuscular atribuídos à atividade laboral das profissionais de enfermagem, revelando um grave problema à saúde dessa categoria no Brasi( ${ }^{(6-9)}$.

Outro ponto a destacar é que nem sempre os DORT são reconhecidos ou apontados como doença do trabalho, já que, na maioria das vezes, as atividades desempenhadas pelos trabalhadores de enfermagem, em especial as mulheres, no lar, ou seja, as tarefas domésticas, também demandam um desgaste do aparelho osteomuscular, dificultando a comprovação da relação da doença com o trabalho ${ }^{(10)}$.

Inseridas no cenário hospitalar, as trabalhadoras de enfermagem portadoras de DORT enfrentam dificuldades inerentes ao processo fisiopatológico da doença, uma vez que os sintomas incluem não apenas a dor e desconforto constantes mas, também, a diminuição de força, edema e enrijecimento articular, tornando os DORT um sério problema de saúde no seu cotidiano(10).

Nesse sentido, este estudo, parte de trabalho de doutorado, buscou compreender o fenômeno ser mulher, trabalhadora de enfermagem, portadora de DORT, uma vez que a vivência profissional das pesquisadoras tem evidenciado a necessidade de aproximar-se do cotidiano sofrido dessas mulheres, vislumbrando a possibilidade de transformações, não apenas na organização do trabalho, mas nas formas de assistir a saúde dessas trabalhadoras.

\section{TRAJETÓRIA METODOLÓGICA}

\section{Tipo de estudo}

Para desvelar o fenômeno ser mulher trabalhadora de enfermagem portadora de DORT e compreender o significado verdadeiro desta experiência, optou-se pela pesquisa qualitativa e pelo referencial filosófico da fenomenologia existencial de Martin Heidegger.

O foco da pesquisa qualitativa está na interpretação, com ênfase na subjetividade, merecendo grande destaque pela própria natureza do seu conhecimento em ciências humanas, sociais e da saúde ${ }^{(11)}$.

A pesquisa fenomenológica representa um método interessante para a área de enfermagem, pois convida a repensar o caminho qualitativo da existência, a redescobrir o sentido de ser humano no mundo, o que possibilita a compreensão do significado das experiências relativas ao processo saúde-doença vividas nas diversas fases do ciclo vital ${ }^{(12)}$.

\section{População e local do estudo}

A pesquisa teve como sujeitos seis mulheres trabalhadoras de enfermagem portadoras de DORT, quatro auxiliares e duas técnicas de enfermagem. A escolha dos sujeitos foi definida pelo acesso aos dados do Serviço de Assistência Médica e Social ao Servidor (SAMSS) de um hospital escola situado na região oeste do município de São Paulo. As áreas de atuação das trabalhadoras eram clínicas cirúrgicas de ortopedia, geriatria, maternidade e central de material e esterilização. Julgamos importante elucidar esses dados para melhor caracterização dos sujeitos estudados, no entanto, esses fatores não interferiram nos resultados do estudo.

\section{Coleta de dados}

Antecedendo a coleta dos discursos, o projeto da pesquisa foi avaliado e aprovado pelo Comitê de Ética em Pesquisa da Escola de Enfermagem da Universidade de São Paulo (Protocolo 405/2004) e pela Comissão de Ética para Análise de Projetos de Pesquisa da Diretoria Clínica do Hospital das Clínicas da Faculdade de Medicina da Universidade de São Paulo (Protocolo 499/2005).

Considerando o que preconiza a Resolução 196/96, sobre as diretrizes e normas regulamentadoras de pesquisa com seres humanos, as mulheres entrevistadas foram esclarecidas sobre o objetivo da pesquisa bem como sobre a manutenção do sigilo, o anonimato de sua pessoa e do direito de participar ou não do estudo. Após tais esclarecimentos, foi solicitada a assinatura do Termo de Consentimento Livre e Esclarecido.

Primeiramente foi mantido contato telefônico com as trabalhadoras de enfermagem previamente selecionadas pela listagem do SAMMS, onde foi realizado o convite para a participação do estudo. As entrevistas com as trabalhadoras que aceitaram participar do estudo foram agendadas em data e horário escolhidos por elas, possibilitando maior liberdade e o mínimo de interferência na realização dos encontros, fatores essenciais na pesquisa fenomenológica. A identidade das mulheres foi preservada, utilizando-se nomes fictícios para a identificação de cada discurso colhido. As entrevistas foram gravadas em fita K7 e norteadas pela seguinte questão: Costaria que você me contasse a sua experiência, como é para você ser mulher, trabalhadora de enfermagem convivendo com um distúrbio osteomuscular? 


\section{Análise dos discursos}

Para análise dos discursos realizou-se a transcrição na íntegra, a leitura e releitura, a busca de unidades de significado e a identificação de categorias, segundo o referencial filosófico de Martin Heidegger.

\section{RESULTADOS E DISCUSSÃO}

A análise dos discursos possibilitou a identificação de quatro categorias: "O ser- no- mundo vivenciando os DORT", "A angústia da trabalhadora de enfermagem que vivencia os DORT", "A trabalhadora de enfermagem vivenciando a ambigüidade da solicitude" e "A transcendência da trabalhadora de enfermagem vivenciando o DORT". No presente estudo, optou-se por apresentar a categoria "A angústia da trabalhadora de enfermagem que vivencia os DORT", considerando que esta representa mais significativamente o cotidiano das mulheres que experienciam os DORT, uma doença crônica e incapacitante.

A vivência dos DORT faz emergir nas trabalhadoras uma variedade de sentimentos, entre os quais a angústia que, segundo Heidegger ${ }^{(13)}$, pode ser definida como a consciência de que somos ser-para-morte, seres para o fim.

No contexto do adoecer, as trabalhadoras de enfermagem experimentam muitas limitações, considerando que, na maioria das vezes, essas mulheres têm uma vida ativa, respondendo pelas atividades domésticas e profissionais, e a nova situação as obriga a tomar consciência de que a vida mudou; e que as transformações acarretadas pela doença já se instalaram e o amanhã é incerto na vida delas. Assim, as manifestações dolorosas, as incertezas quanto às habilidades físicas e quanto às respostas frente aos tratamentos fazem as trabalhadoras vivenciar a angústia, conforme apresentado a seguir:

...não vejo melhora, sabe... de tudo eu já fiz, tudo...eu falei, chega uma hora que você cansa né, eu logo vô parar também porque eu já tô cansada, sabe de você ficar pra cima e pra baixo, faz uma coisa, faz outra. Aí se tem que deixa casa, deixa filho, deixa tudo... pra ficá ali só investir em você, só... e você não vê resultado...(Laura)

Na maioria das mulheres, o cansaço e a desmotivação estão relacionados com as respostas ineficazes ante os tratamentos, já que nos discursos pudemos perceber que elas investem em diversas formas de tratamento, não somente na terapêutica medicamentosa, como em fisioterapia, acupuntura, psicoterapia, entre outros.

Os DORT não são causados por um esforço repetitivo qualquer, as causas vão além dos sintomas físicos, passam pela organização do trabalho, dificuldades interpessoais bem como os fatores ergonômicos. É certo que pacientes com DORT apresentam evidências de depressão, ansiedade e angústia. Porém, em geral, trata-se de quadros decorrentes de situações concretas de perda da identidade no trabalho, na família e no círculo social, além da penosidade de se submeter aos tratamentos longos, de resultados lentos e incertos, e perícias nas quais estão sendo constantemente questionados como se estivessem querendo "estar doentes" (14).
Assim, um dos principais problemas dos DORT é que dificilmente um único tipo de tratamento é suficiente para amenizar os sintomas dolorosos, ou seja, para que os pacientes sintam uma melhora efetiva é necessária a associação de diferentes tratamentos. É importante salientar, ainda, que o afastamento das atividades profissionais representa um dos fatores de maior relevância no controle dos sintomas ocasionados pela doença. No entanto, nem sempre isto é possível, conforme aponta a literatura.

Estudo realizado com uma equipe de enfermagem de uma unidade de terapia intensiva pós-operatória evidenciou que, mesmo apresentando dores durante a jornada de trabalho, e com uma elevada taxa de absenteísmo, muitos trabalhadores continuavam ativos ${ }^{(8)}$.

Curiosamente, as mulheres, que trazem na sua história a essência do cuidar, muitas vezes despreocupam-se com a sua própria saúde, relegando o tratamento para um segundo plano, adoecendo solitárias com suas queixas tímidas em relação ao sofrimento por DORT ${ }^{(10)}$.

Portanto, observa-se que há uma resistência ao afastamento do trabalho não apenas por parte dos profissionais médicos, mas das próprias trabalhadoras que convivem com os DORT, conforme pudemos observar nos discursos.

O relato de Marília mostra que o agravamento da doença exigiu que essa trabalhadora se afastasse do trabalho, gerando nela um sentimento muito grande de incapacidade, pois para ela seria impossível um dia exercer sua profissão novamente:

...em alguns momentos achei que eu não pudesse mais trabalhar mesmo aí comecei a fazer um tratamento intenso com psicoterapia... Eu tava precisando mesmo (choro, silêncio) (Marília)

Por outro lado, somente na angústia mais profunda é que se abrem oportunidades para a cura, ou seja, na fase mais difícil da doença, a angústia experimentada pela trabalhadora foi tão intensa que repercutiu de forma decisiva em seu tratamento, já que ela reconheceu a necessidade de procurar outras alternativas para o seu tratamento, momento em que ela investe na psicoterapia.

Heidegger $^{(13)}$ afirma que somente na angústia subsiste a possibilidade de uma abertura privilegiada, na medida em que ela singulariza, ou seja, retira a pre-sença de sua de-cadência e Ihe revela possibilidades. Isso significa que o ser humano só pode investir nele próprio quando se percebe e aceita sua real situação.

A literatura evidencia que os trabalhadores têm dificuldade em aceitar a doença, procurando um tratamento específico quando os sintomas já são mais graves e comprometeram grande parte das funções ${ }^{(3)}$.

Ao vivenciar a angústia por estar acometida por DORT e se ver impossibilitada para o trabalho e para uma diversidade de tarefas simples do cotidiano, as trabalhadoras podem re-elaborar sua vida mediante as novas condições. Porém, este processo é demorado e a dificuldade em aceitar as limitações e a incapacidade torna ainda mais sofrida a convivência com a doença, conforme contam as trabalhadoras: 
...e para aceitar, como eu estava te falando é duro, você é uma pessoa ativa, de repente você não pode fazer mais nada... (Inês)

...você muitas vezes fica triste, chora...porque você fica vendo pessoas da mesma idade que você e que fazem tudo, tem aquela disposição, não sentem dor nenhuma... e você com aquelas dores horríveis...(Eliete)

Os trechos de Eliete e de Inês evidenciam a importância que atribuem às limitações, fazendo comparações do seu estado de saúde atual, com o estado de saúde anterior ou mesmo de outras pessoas na mesma idade, revelando a angústia por dar-se conta de uma fragilidade que é individual.

As proposições de Heidegger ${ }^{(13)}$ revelam que a fragilidade da existência é algo imperceptível ao ser humano no cotidiano, porém, é com base na percepção singular de que somos essencialmente finitos e de que os nossos dias estão contados, é que se pode experimentar a angústia.

Dessa forma, compreendemos que à medida que ocorre o avanço do processo fisiopatológico dos DORT, inevitavelmente, as mulheres sentem a angústia, pois elas não criam mais expectativas sobre a sua condição, sentindo a fragilidade da existência e a imprevisibilidade dos acontecimentos.

Notamos que elas se comparam também a outros profissionais da equipe de enfermagem, ressaltando que hoje elas estão "assim", mas que já foram muito úteis e sacrificaram suas vidas pelos pacientes e pela manutenção da qualidade de assistência para o funcionamento adequado do hospital:

...porque olha, ali... Eu já dei meu sangue ali viu... (Laura)

...uma das pessoas me disse, tem 20 anos que eu trabalho nesse mesmo setor, e eu nunca tive nada... Mas depende do que você faz e do que você deixa de fazer. Não era que nem a gente que só ficava dobrando e guardando roupa, fazendo os pacotes, as compressas, são bastante coisa, né... (Neide)

A fala de Neide aponta sua inquietação com a opinião do colega, porque o mesmo trabalhou há muito tempo no mesmo setor em que ela trabalhava e nunca teve problemas de saúde. O discurso deste colega desencadeia na trabalhadora de enfermagem uma espécie de revolta, no qual ela explicita que nem todos os trabalhadores se envolvem seriamente com a dinâmica de trabalho, sobrecarregando os outros trabalhadores. Por outro lado, denuncia a sua angústia imposta pelas limitações que são individuais, assim como a predisposição para a doença.

Nesse aspecto, as trabalhadoras de enfermagem submetem-se constantemente a condições de trabalho inadequadas, extrapolando as inúmeras habilidades exigidas no desempenho das suas funções, estando muito suscetível à lesões músculo esqueléticas, atribuídas principalmente a fatores ergonômicos e posturais inadequados, presentes na rotina de trabalho assistencial ${ }^{(7,10)}$.

$\mathrm{Na}$ realidade, percebemos que as mulheres trabalhadoras de enfermagem carregam em si uma certa culpa por terem adquirido os DORT, embora reconheçam a influência dos fatores externos no aparecimento da doença, assim, ao indagá-las sobre como é conviver com a doença, elas expressam um intenso desejo de continuar trabalhando na eqüidade dos demais profissionais da equipe de enfermagem:

...eu me cobro, porque eu gostaria de trabalhar com os meus colegas ombro a ombro, de igual para igual. Então, às vezes eu não consigo, porque tem algumas restrições, mas eu acho que eu me igualo assim em conhecimento... (Marília)

No corpo de Marília estão as marcas dos DORT, caracterizadas pela dor, perda de força e pela restrição para determinados movimentos, o que torna mais evidente ainda sua fragilidade. No entanto, seu discurso demonstra que de alguma maneira ela percebeu que o seu conhecimento também é uma ferramenta importante para o cotidiano do trabalho.

Ser mulher, trabalhadora de enfermagem, vivenciando os DORT, traz à tona sentimentos diversos que envolvem a questão da fragilidade do corpo, traduzida pelas inúmeras limitações, pela dor e pela dificuldade em realizar determinados movimentos e pela impossibilidade de "ser a mesma" de antes:

...e você não tem assim uma esperança que você vai conseguir voltar a ser o que você sempre foi... (Eliete)

O sentimento expresso por Eliete demonstra sua falta de esperança em ser a mesma pessoa, momento em que ela experiencia a angústia, porém é diante dessa vivência que ela encontra-se a si-mesma e pode ser ela própria.

Heidegger ${ }^{(13)}$ cita que a morte é, entre as possibilidades, a mais pessoal, mais ímpar do ser-aí e essa é justamente a fonte da angústia. Nesse aspecto, a mulher trabalhadora de enfermagem convivendo com os DORT, ao pensar em suas limitações, suas restrições para o trabalho, aproxima-se de sua finitude, onde poderá viver de forma autêntica ou inautêntica, em função do medo de se confrontar consigo mesma e com o seu ser-para-o-fim.

...a gente começa assim, quando tem uma lesão assim, na mão, mão direita, quando imobilizava a mão não conseguia fazer nada com a mão esquerda, queria morrer... (Marília)

A verbalização de Marília revela que seu mundo-vida foi intensamente modificado em razão da doença e quando, ao longo do discurso, refere "mão direita", evidencia-se que na sua relação com o mundo e com as coisas do mundo ela percebe sua incapacidade. Passa assim, a questionar sua existência, onde o "querer morrer" parece o fim de tudo, o fim de se deparar com uma fragilidade tão íntima, tão sua, explicitando a angústia desta trabalhadora que se percebe enquanto ser-para-morte.

Além disso, em vários momentos durante as entrevistas, as mulheres se remetem a acontecimentos passados, recordando-se de fatos marcantes da doença, os quais as sensibilizam 
ainda mais, pois trazem a elas a consciência do adoecimento e lembranças do agravamento do seu estado.

Na maioria das vezes, essas lembranças estão ainda vivas na mente das mulheres, pois repercutiram imensamente em suas vidas, fazendo com que outras pessoas participassem da sua doença e visualizassem ainda mais as suas dificuldades e o agravamento do seu estado como no trecho subseqüente:

...se eu pegar um peso hoje, eu vou embora na cadeira de rodas, como eu já fui uma vez... cheguei no pronto-socorro de cadeira de rodas, travei, não deu para andar, foi uma cena assim terrível, que eu não quero mais lembrar disso... (Júlia)

Algumas lembranças de eventos que marcaram a limitação ou que evidenciaram ainda mais as características da doença fazem emergir nessas trabalhadoras o sentimento de angústia. Os comprometimentos, que não são poucos, as inúmeras adaptações que elas necessitam fazer para continuar interagindo no mundo e com as coisas do mundo obrigam as mulheres a remeter um olhar mais profundo para a sua existência, transmitindo a elas a noção exata de que somos ser-para-a-morte, dada a consciência que ali se faz presente por ocasião do adoecimento.

A vivência dos DORT é experimentar um mundo novo, um mundo repleto de alterações físicas, marcadas pela dor, por efeitos colaterais dos medicamentos e mais, por dificuldades físicas próprias do aparelho osteomuscular. Após o início da sintomatologia, e à medida que a doença se agrava, a rotina de vida dessas mulheres apresenta uma série de modificações, caracterizadas por limitações nos movimentos e por sensação de incapacidade para inúmeras atividades do seu dia-a-dia ${ }^{(10)}$.

O aborrecimento, a tristeza e o medo aparecem nos discursos das mulheres trabalhadoras de enfermagem que convivem com os DORT. Assim, à medida que elas vão se percebendo em um novo contexto de vida, elas se questionam quanto ao futuro, quanto ao prognóstico da sua doença e inevitavelmente fazem reflexões acerca das suas capacidades e limitações. O futuro passa então a ser mais incerto, mais obscuro, e, pouco a pouco, estas mulheres admitem a sua fragilidade enquanto ser-no-mundo.

O caminho até este estágio é longo e incerto, pois os profissionais ainda não têm muito domínio no diagnostico precoce e rápido. As patologias musculoesqueléticas que podem provocar sintomas dolorosos são inúmeras, mas o que ocorre na pratica clinica diária é que, dentro do conhecimento cientifico atual, não se consegue ainda diagnosticar a razão etiológica do quadro doloroso na maioria dos pacientes ${ }^{(14)}$.

Os discursos abaixo demonstram a náusea ontológica, manifestada pelo aborrecimento, tristeza e principalmente dúvida, nos quais as trabalhadoras se questionam e questionam aos profissionais da saúde quanto às chances de recuperação, de melhora e do seu próprio futuro:

...eu vim aqui doutor para o senhor tentar resolver o meu problema, que não é possível eu fazer fisioterapia e não ver um resultado... Eu já estava tão aborrecida porque assim você faz a fisioterapia, tudo bem, mas você continua fazendo força física, então eu melhorava, fazia uma semana a fisioterapia e eu melhorava, mas o primeiro peso que eu pegava pronto...maca, cama, de paciente...então eu me aborreci de tal maneira...(Neide)

A verbalização de Neide evidencia a dificuldade para aceitar a sua nova realidade e, embora tenha consciência das suas limitações, ela procura esforçar-se, especialmente no trabaIho. No entanto, quando as manifestações dolorosas surgem em decorrência do esforço físico realizado, manifesta aborrecimento, esperando que haja uma solução mais imediata e eficiente para o seu problema.

Ao compreender o mundo vida das trabalhadoras que vivenciam os DORT, evidencia-se a esperança de uma recuperação, conforme relata Inês:

...eu sempre pensava assim, tanta gente já operou e ficou boa, mas cada caso é um caso, o meu caso é diferente ele falou:- O seu caso é diferente não tem nada a ver... Aí eu falei puxa vida doutor, eu tinha esperança que você ia me dar uma solução,olha no dia que eu falei com ele eu fiquei bem chateada....(Inês)

No entanto, ao longo do tempo, vão percebendo a cronicidade da doença e, após procurarem diferentes tratamentos e opiniões profissionais variadas, demonstram decepção, e sofrem pela realidade que a elas se apresenta.

Ao serem diagnosticados com esta patologia ficam deprimidas, angustiadas, sentindo-se inferiores, impotentes, muitas iniciam o uso de uma gama de medicamentos diários que, muitas vezes, não têm o resultado esperado e vão à procura de exaustivos tratamentos, culminando com longos períodos de afastamentos do trabalho(14)

Além disso, os discursos evidenciaram que as mulheres precisam ouvir uma resposta mais assertiva em relação à doença e, infelizmente, muitos profissionais especialistas não fornecem esclarecimentos claros, objetivos. Na maioria das vezes, isso ocorre na tentativa de amenizar o sofrimento dessas mulheres. No entanto, à medida que eles procuram ocultar informações, as incertezas e dúvidas, associadas ao medo do futuro, trazem ainda mais angústia:

...o ortopedista daqui falava: 'Você está pegando peso, mas você não pode pegar peso'... Aí eu me perguntava: 'que saída eu vou ter?'(Inês)

Pudemos observar que, após negar a doença, lutar contra os sintomas, insistir nas tarefas e no trabalho, a mulher trabaIhadora de enfermagem precisa chegar no seu limite quanto à dor e também quanto às limitações, momento em que ela olha para si, como diz Júlia:

... e eu sou uma funcionária agora que eu tenho restrição de serviço, eu não posso pegar peso, manuseio de pacientes, pesos e então é assim agora a minha vida, entendeu? (Júlia) 
Segundo Heidegger ${ }^{(13)}$, ao reconhecer a possibilidade da morte é que o ser humano encontra sua autenticidade, já que a morte é uma possibilidade incondicional e insuperável, portanto, para o autor, a angústia é um tipo de náusea ontológica que invade o ser humano quando este está perto de compreender a incerteza de sua existência.

Ao compreender a mulher trabalhadora de enfermagem vivenciando os DORT, percebemos que a trajetória percorrida pelas mulheres é extremamente árdua, porém quando elas se reconhecem, quando o ser-aí se assume enquanto trabalhadora portadora de DORT, os caminhos parecem se abrir, a mulher se reconhece como era e como está, permitindo que a sua relação com os outros seja estabelecida diante da sua nova condição.

...quando eu consegui o CAT eu soube que legalmente eu tinha um respaldo, o hospital estava reconhecendo... eu tenho um respaldo assim de pedir uma indenização para a minha lesão...(Marília)

O relato de Marília revela que, no momento em que ela, "ser de intersubjetividade", aceitou que o ser-com estava pautado na verdade do seu ser-aí, passa a compreender que, mesmo diante de uma situação tão difícil, ela pode se beneficiar dos aspectos legais inerentes ao seu processo de saúde-doença.

...então uma hora realmente eu não tive alternativa, eu tive que decidir, eu não né, quem decidiu foi a médica, eu chorei pra caramba.... No dia que ela me mandou para o INSS comecei a chorar, mas tudo bem... ela entendeu... Então é isso, a gente vai levando o melhor que a gente pode... (Inês)

Para viver de forma autêntica, a mulher precisa enfrentar sua nova situação; a pre-sença é e está essencialmente na verdade, a abertura só se dá quando a pre-sença está na ver$\operatorname{dade}^{(13)}, \mathrm{e}$, por mais que seja difícil, essa trajetória parece indispensável para que ela possa re-elaborar novas maneiras de ser-mulher-no-mundo.

Ao atravessar pelas dificuldades inerentes ao processo de adoecimento pelos DORT, as mulheres trabalhadoras de enfermagem vivenciam sentimentos de perda, de revolta e tristeza, mas a partir do momento em que admitem a sua doença e a sua nova condição, abraçam novos objetivos, atribuindo novo significado a sua existência ${ }^{(9)}$

Ponderando sobre os aspectos apresentados, evidencia-se a necessidade de que as instituições e trabalhadores atuem em conjunto, no sentido de planejarem e implementarem estratégias de mudanças nas estruturas e comportamentos para provocar melhoria das condições de trabalho e promover a qualidade e satisfação no trabalho dos profissionais de saúde. Considerando que a atual conformação dos serviços de saúde fundamenta-se em gestões que nem sempre consideram a organização do trabalho como espaços coletivos de aprender e de compartiIhar, a construção conjunta, envolvendo, de fato, todos, é um processo que requer novos arranjos de poderes e de saberes que certamente podem dar outros contornos para o trabalho em saúde e em especial para o trabalho da enfermagem ${ }^{(15,16)}$.

\section{CONSIDERAÇÕES FINAIS}

A análise dos discursos segundo os pressupostos de Martin Heidegger sobre o existencialismo permitiu compreender que a experiência de vivenciar os DORT faz emergir sentimentos como a angústia, onde as mulheres passam a questionar sua existência no mundo e a fragilidade do seu ser. Quando as trabalhadoras de enfermagem percebem que o mundo-vida é um mundo que deve ser re-criado, considerando as perdas advindas do processo de adoecimento, elas passam a interagir com o mundo e com os outros, sob outra ótica, o que significa aceitar sua realidade, e aprender a lidar com as transformações.

Ao perceber-se mulher trabalhadora de enfermagem portadora de DORT e estando aberta para uma nova forma de ser-no-mundo, é possível conviver com a doença de maneira menos sofrida, pois este é o único caminho para que essa mulher possa re-começar sua história, aceitando sua nova condição enquanto ser no mundo, transcendendo a doença.

Os resultados apresentados neste estudo direcionam para um repensar nas condições de trabalho e nas possíveis estratégias para transformar o cenário do adoecer por DORT na enfermagem, apontando para a necessidade de mais estudos nessa temática.

\section{REFERÊNCIAS}

1. Salim CA. Doenças do trabalho: exclusão, segregação e relações de gênero. Perspect 2003; 17(1): 11-24.

2. Verthein MAR, Minayo-Gomez C. A construção do sujeito-doente em LER. Hist Cienc Saude Manguinhos 2000; 7(2):329-47.

3. Ministério da Saúde. Secretaria de Políticas de Saúde. Protocolo de investigação, diagnóstico, tratamento e prevenção de Lesão por Esforços Repetitivos/ Distúrbios Osteomusculares Relacionados ao Trabalho. Brasília; 2000.

4. Assunção AA, Almeida IM. Doenças osteomusculares relacionadas com o trabalho: membro superior e pescoço.
In: Mendes R. São Paulo: Atheneu; 2003. p.1502-39.

5. Ministério da Saúde. Secretaria de Políticas de Saúde. Departamento de Ações Programáticas e Estratégicas. Área Técnica de Saúde do Trabalhador. Lesões por Esforços Repetitivos (LER) e Distúrbios Osteomusculares Relacionados ao Trabalho (DORT). Brasília; 2001. (Série A. Normas e Manuais Técnicos, 103).

6. Leite PC. Morbidade referida pelos trabalhadores de enfermagem de um centro de material e esterilização especializado em ortopedia. [dissertação]. São Paulo: Escola de Enfermagem da USP; 2001. 
7. Parada EO, Alexandre NMC, Benatti MCC. Lesões ocupacionais afetando a coluna vertebral em trabalhadores de enfermagem. Rev Lat Am Enferm 2002; 10 (1):64-9.

8. Drummond AS, Sampaio RO, Rodrigues GC. Distúrbios Osteomusculares relacionados ao trabalho (DORT): estudo com a equipe de enfermagem em uma unidade de terapia intensiva de pós-operatório (UTI-PO). Rev Socerj 2003; 16(supl.A). Disponivel em: http// www.socerj.org. br/temas/21 enfer.pdf/ (16 mar.2004).

9. Leite PC, Merighi MAB, Silva A. O cotidiano de trabaIhadoras de enfermagem acometidas por distúrbios osteomusculares relacionados ao trabalho (DORT) sob a luz da fenomenologia heideggeriana. Online Braz J Nurs (OBJNISSN 1676-4285). 2007; 6 (3). Available at htpp//www. uff.br/objnursing. Acesso em 16/01/2009.

10. Leite PC. A vivência de mulheres trabalhadoras de enfermagem que apresentam Distúrbios Osteomusculares Relacionados ao Trabalho (DORT): uma abordagem compreensiva da fenomenologia existencial [Tese]. São Paulo: Escola de Enfermagem da USP; 2006.
11. Moreira DA. O método fenomenológico na pesquisa. São Paulo: Pioneira Thompsom; 2002.

12. Merighi $M A B$. Fenomenologia In: Merighi $M A B$, Praça NS. Abordagens teórico-metodológicas qualitativas: a vivência da mulher no período reprodutivo. Rio de Janeiro: Guanabara Koogan; 2003.

13. Heidegger M. Ser e tempo. Trad. de Marcia Sá Cavalcante Schuback. 13a ed. Petrópolis: Vozes; 2004.

14. Barbosa MSA, Santos RM, Trezza MCSF. A vida do trabalhador antes e após a Lesão por Esforço Repetitivo (LER) e Doença Osteomuscular Relacionada ao Trabalho (DORT). Rev Bras Enferm 2007; 60(5) : 491-96.

15. Mantovani MdF, Lacerda MR,Ulbrich E, Bandeira JM, Gaio DM. Panorama da produção do conhecimento em enfermagem na saúde do trabalhador: impacto e perspectivas. Rev Bras Enferm 2009; 62(5):784-88.

16. Pereira M JB, Fortuna CM, Mishima SM, Almeida MCP de, Matumoto S. A enfermagem no Brasil no contexto da força de trabalho em saúde: perfil e legislação. Rev Bras Enferm 2009; 62(5): 771-77 